\title{
The Need and Safety of Mineral Supplementation in Adults with Obesity Post Bariatric Surgery-Sleeve Gastrectomy (SG)
}

\author{
Agata Wawrzyniak $^{1}$ (D) Monika Krotki ${ }^{1}$
}

Received: 28 April 2021 / Revised: 27 July 2021 / Accepted: 27 July 2021 / Published online: 4 August 2021

(c) The Author(s) 2021

\begin{abstract}
Purpose Most of the research indicated that daily dietary intake of minerals in SG patients was lower than the current recommendations. The aim of the study was to assess the need and safety of a mineral supplementation practice in adults with obesity, at 3,6, and 9 months post bariatric surgery-sleeve gastrectomy (SG).

Methods The study included 24 women and 6 men. Based on a 4-day food record questionnaire, mineral and calorie intake was calculated at 3,6, and 9 months after bariatric surgery (SG). Furthermore, an interview on supplement intake was also conducted.

Results It was found that in both men and women, there was a dietary intake deficiency of calcium (97\% of respondents), potassium (97\%), magnesium (83\%), sodium (60\%), and zinc (53\%). In women, the deficiencies also included iron (50\%) and copper (29\%). Only $72 \%$ of the patients took dietary supplements. The applied supplementation did not adjust for the required intake of calcium in all of the patients, as well as the intake of magnesium in the male patients. Low intake of sodium and potassium were not supplemented and should be corrected by diet modification. The patients did not require supplementation of phosphorus or manganese, while male patients did not require iron or copper supplementation. The dietary and/or supplemental intake of minerals did not exceed the tolerable upper intake level (UL).

Conclusion The results of the study confirm the need to implement personalized mineral supplementation for bariatric surgery patients.
\end{abstract}

Keywords Sleeve gastrectomy (SG) $\cdot$ Adults $\cdot$ Mineral intake $\cdot$ Mineral supplementation

\section{Introduction}

Key Points

- To improve the implementation of nutritional recommendations post bariatric surgery in women, special attention should be paid to intake of calcium with dietary supplements and in men to the correct supply of calcium and magnesium.

- Both men and women should be encouraged to modify their diet to improve potassium and also sodium intake as both minerals are not usually recommended in the form of supplements.

- In all of SG patients, zinc supplementation as well as the supplementation of iron and copper in women properly adjusted deficient intake from food products.

- Phosphorus and manganese supplementation proved to be unjustified in all SG patients, as well as iron and copper in men.

Agata Wawrzyniak

agata_wawrzyniak@sggw.edu.pl

1 Department of Human Nutrition, Institute of Human Nutrition Sciences, Warsaw University of Life Sciences (WULS-SGGW), 159C Nowoursynowska Str, 02-776 Warsaw, Poland
It is generally accepted that surgical treatment is a documented and effective method of treating pathological obesity, leading to long-term weight loss, as well as the remission of comorbidities (heart disease, metabolic disorders, lipid disorders, type 2 diabetes, sleep apnea, osteoarthritis) and decreasing risk of death [1-4]. In the world, the most common bariatric surgery is sleeve gastrectomy (SG) $[2$, 5]. This restrictive procedure [6] causes a limitation of food intake by decreasing the size of the stomach and reducing the ability to produce the hunger hormone-ghrelin-in the stomach. By decreasing the capacity of the stomach, the patient is unable to consume larger portions of food, as prior to the procedure, and the passage of food is accelerated through the digestive tract, which leads to a decrease in nutrient absorption and body mass [5, 7-9]. A significant side effect of all bariatric operations is nutritional deficiency, among other mineral insufficiencies, which can 
result in serious clinical consequences. It was observed that after SG and RYGB (Roux-en-Y gastric bypass), the mean daily dietary intake, primarily of calcium, magnesium, and iron, was lower than the current recommendations [10-14]. However, these studies have not shown whether the recommended mineral supplementation covers dietary deficiencies and whether or not there is a need to alter the supplementation practice due to further deficiencies or excessive intake. Thus, the aim of the study was the assessment of whether applied routine supplementation is sufficient in preventing mineral dietary deficiencies in patients having undergone bariatric surgery-sleeve gastrectomy in later post-surgical periods, i.e., at 3,6 , and 9 months after the procedureand whether the scope of the administered supplementation exceeds safe levels.

\section{Methods}

The study followed patients of the General, Oncological and Digestive Tract Surgery Department at the Medical Centre of Postgraduate Education at Orlowski Hospital in Warsaw, Poland. The study received the approval of the Bioethical Commission of the Centre of Postgraduate Education on April 12, 2017 (KB-W-382/2017), as well as the approval of the individual patients.

\section{Study Participants}

The study concerned patients with obesity class III and greater, and with obesity class II with comorbidities, such as heart disease, metabolic disorders, lipid disorders, diabetes, sleep apnea, and osteoarthritis, prior to surgery. The patients undergoing the procedure met the following inclusion criteria: an age range between 18 and 60 years, BMI $\geq 40 \mathrm{~kg} / \mathrm{m}^{2}$, or BMI $35-39.9 \mathrm{~kg} / \mathrm{m}^{2}$ in persons additionally experiencing comorbidities. Exclusion criteria were as follows: inflammation of the digestive tract, chronic oesophagitis, gastric and duodenal ulcers constituting a risk of gastrointestinal bleeding, as well as digestive tract anomalies, severe heart disease and breathing difficulties, alcohol abuse, drug addiction, pregnancy, mental disorders, personality disorders, severe depression, a possible lack of patient engagement in the post-surgical treatment process, an inability to look after oneself, and a lack of due medical care from a caregiver post-surgery $[6,15,16]$.

\section{Procedures}

The study followed SG patients at 3,6, and 9 months postsurgery. Participants completed a questionnaire about their age, dwelling place, education, job activity, and economic status. Dietary intake was assessed by a 4 -day food record covering 3 working days and 1 non-working day. Patients reported all consumed products, meals, and drinks in grams/ milliliters or in household measurements in three study periods. The portion size was defined using photographs of the products and meals showing three size options for each item [17]. The consumed foods were calculated into energy and nutrient units by Polish-developed computer software used to generate national food label composition tables [18]. In this paper, energy intake was reported for each stage of the study as separate mean values for women and men, while mineral intake (sodium, potassium, calcium, phosphorus, magnesium, iron, zinc, copper, and manganese) as a mean value of all three stages, for each subject or for women and men.

Throughout the postoperative follow-up period (including visits in months 3, 6, and 9 after surgery), all patients received dietary recommendations from a dietitian in the form of oral recommendations, a brochure or leaflet, and ready-made menus. The usage of dietary supplements was recommended to each patient by the operating surgeon, patients decided to choose and purchase one of the commercially available supplements. The amount of minerals taken in the form of supplements was calculated on the basis of a verbal interview at each stage of the study (product and dosage amount) and the product composition information on the food label. Usually patients took one tablet of MVMM product daily (Centrum, Vigor, Bodymax). The percentage of patients who did not meet the EAR (estimated average requirement) or AI (adequate intake) Polish recommendations [19] were determined during the 3-, 6-, and 9-month post-surgery time periods, taking into account only diet, as well as diet and supplements. Moreover, the tolerable upper intake level (UL) [20] was used to verify the safety of mineral intake.

\section{Statistical Analysis}

Statistical analysis was carried out using the IBM SPSS Statistics 25 (SPSS Inc., Chicago, IL, USA) software package. Descriptive statistics and distribution normality testing of continuous variables were performed using the Shapiro-Wilk test; the results were presented as mean values, standard deviations, and percentages according to the type of variable. To assess the significance of difference between two independent groups, the Mann-Whitney U test (for continuous variables) or the $\mathrm{chi}^{2}$ test (for nominal variables) were used. To verify the significance between time periods or groups in repeatable measurements, a nonparametric Wilcoxon test (for 2 groups before and after the implementation of supplementation)/Friedman (for 3 period tests) was used, and in the case of the nominal variable for repetitive measurements, the McNemar test (for 2 groups)/W. Kendall (for 3 study periods) was used. The need for supplementation was 
verified using logistic regression analysis. The odds ratio $(\mathrm{OR})$ and $95 \%$ confidence intervals $(95 \% \mathrm{CI})$ were calculated. The reference category was the group without supplementation ( $\mathrm{OR}=1.00)$. The value of $\alpha=0.05$ was considered as statistically significant.

\section{Results}

The study involved 30 ( 24 women and 6 men) bariatric SG surgery patients. The mean age of the female patients was $44 \pm 10$ years and for the male patients $50 \pm 7$ years (Table 1). There was no significant differences between the female and male patients regarding age, dwelling place, education level, and job activity of respondents.

Energy intake at 3, 6, and 9 months after surgery did not differ significantly among women (mean $1084 \mathrm{kcal} /$ day) and among men (mean $1221 \mathrm{kcal} /$ day), as well as the percentage of subjects taking dietary supplements ( $72 \%$ of respondents) $(p>0.05)$. This allowed the assessment of mineral intake between the group consuming only a food-based diet and the group consuming a diet with additional supplements, presented as the average of the three separate month periods (Table 2).

The limited energy intake after SG was associated with mineral deficiencies. Dietary sodium in $60 \%$ of subjects was lower than adequate intake. Dietary intake of potassium and calcium met recommendation only in the case of one male patient, while the recommendation for magnesium was met by only 5 women. In contrary, phosphorus intake from food in almost all of the patients (29) exceeded the nutritional recommendation (Fig. 1, Table 3).

Supplementation did not change the intake of sodium and potassium, as these minerals were not present in the

Table 1 Participant characteristics

\begin{tabular}{llll}
\hline Characteristics & Women $(n=24)$ & Men $(n=6)$ & $p$ value \\
\hline Age (years) & $44 \pm 10^{*}$ & $50 \pm 7$ & $0.312^{* * *}$ \\
$\begin{array}{l}\text { Place of dwelling }(\% n) \\
\quad 13\end{array}$ & 0 & \\
$\quad$ Village & 13 & 50 & \\
$\quad$ Town $<100,000$ & 45 & 50 & \\
$\quad$ City $>100,000$ & 42 & & $0.215^{* * * * *}$ \\
Education (\% $n)$ & & 50 & \\
$\quad$ Primary & 21 & 50 & \\
$\quad$ Secondary & 54 & 0 & $0.400^{* * *}$ \\
$\quad$ Higher & 25 & & \\
Job activity $(\% n)$ & & 17 & \\
$\quad$ No & 33 & 83 & \\
$\quad$ Yes & 67 & &
\end{tabular}

*mean $\pm \mathrm{sd}$; **Mann-Whitney U test; $* * *$ chi $^{2}$ test; $p \leq 0.05$ statistically significant difference
Table 2 Diet energy and usage of dietary supplements in post bariatric (SG) patients

\begin{tabular}{|c|c|c|c|c|}
\hline \multirow[t]{2}{*}{ Factor } & \multicolumn{3}{|c|}{ Month after bariatric surgery } & \multirow[t]{2}{*}{$p$ value } \\
\hline & $\begin{array}{l}3 \text { rd } \\
(n=30)\end{array}$ & $\begin{array}{l}\text { 6th } \\
(n=30)\end{array}$ & $\begin{array}{l}9 \text { th } \\
(n=30)\end{array}$ & \\
\hline \multicolumn{5}{|c|}{ Energy intake (kcal) } \\
\hline $\begin{array}{l}\text { Women } \\
\qquad(n=24)\end{array}$ & $1083 \pm 326^{*}$ & $1110 \pm 293$ & $1058 \pm 287$ & $0.185 * *$ \\
\hline $\operatorname{Men}(n=6)$ & $1419 \pm 293$ & $1123 \pm 260$ & $1121 \pm 201$ & 0.280 \\
\hline \multicolumn{5}{|c|}{ Multicomponent supplement used (\%n) } \\
\hline $\begin{array}{l}\text { Women } \\
\qquad(n=24)\end{array}$ & 79 & 67 & 63 & $0.156 * * *$ \\
\hline $\operatorname{Men}(n=6)$ & 83 & 83 & 67 & 0.368 \\
\hline
\end{tabular}

${ }^{*}$ mean $\pm \mathrm{sd}$; **Friedman test; ***W. Kendall test; $p \leq 0.05$ statistically significant difference

supplements. The use of supplements did not affect the adequacy of phosphorus intake, because within the whole group undertaking the study, only one woman had intake that was too low. This woman did not take supplements throughout the period considered for this study. Although 25 patients $(83 \%)$ were taking supplements with calcium (up to $162 \mathrm{mg}$ Ca per day), the supplemental dosage was insufficient to achieve nutritional adequacy for calcium in $88 \%$ of the women and in $67 \%$ of the men. The supplemental contribution of calcium supply ranged from 0 to $30 \%$ and was too low. Among macrominerals, supplementation significantly increased the nutritional adequacy intake of only magnesium $(\mathrm{OR}=15.17, p<0.001)$, i.e. the total intake met the estimated average requirement in $53 \%$ of the patients. Nevertheless, total intake was too low in one third of the patients (in $25 \%$ of women and $50 \%$ of men).

In the case of microminerals, the supply of iron and copper from a food-only diet caused deficiencies in 50\% and $29 \%$ of the women, respectively. In men, the dietary intake of these minerals achieved adequacy and there was no need for supplementation. Deficient zinc intake from a food-only diet was observed in $53 \%$ of the respondents, i.e., $46 \%$ of the women and $83 \%$ of the men (Fig. 2). Supplementation significantly improved the intake of iron, zinc, and copper in women. Deficient intake of these elements was found in only $8 \%$ (iron, zinc) and $4 \%$ (copper) of the women, who did not use supplements. Similarly in men, deficient zinc intake was observed in only one man who did not use supplements. Manganese supplementation occurred to be unjustified for all respondents, except for 1 person, as manganese intake from a food-only diet met the recommendation without supplementation.

Only in the case of women did the intake of iron (in 17\%), zinc (in 25\%), and copper (in 8\%) from supplements exceed the intake of these minerals from the food diet; however, none of these elements exceeded the safe UL. 
Fig. 1 Mean dietary and supplement macromineral intakes by women $(\mathbf{W})$ and men $(\mathbf{M})$ tested at 3,6 , and 9 months after bariatric surgery (SG) (all data expressed as $\mathrm{mg} /$ day)
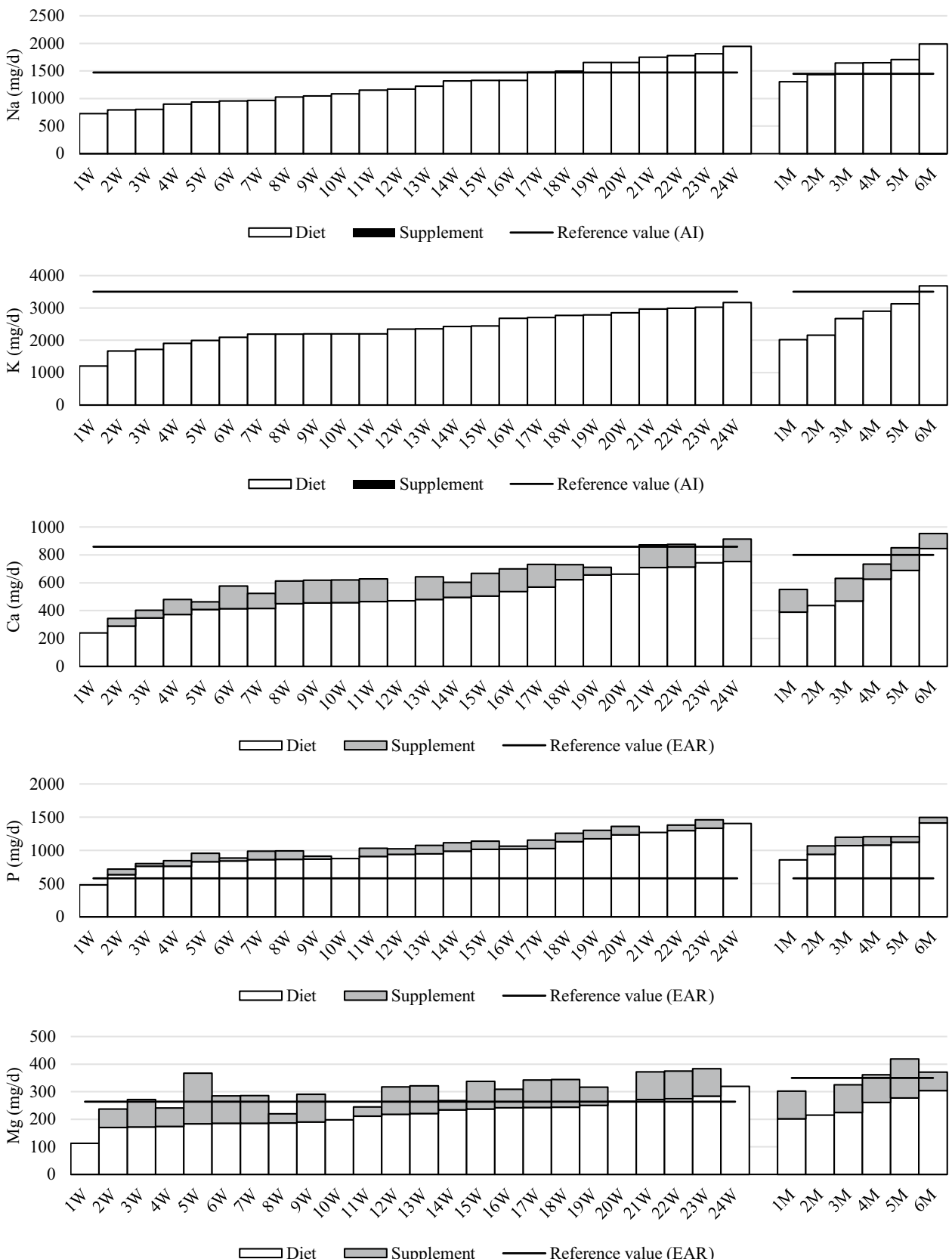

\section{Discussion}

The main observations of the study revealed that (1) the limited energy intake after sleeve gastrectomy is associated with irregularities of mineral intake, and patients require personalized supplementation; (2) the applied supplementation did not adjust to the required intake of minerals in patients; nevertheless, none of the patients exceeded the UL intake of minerals with diet and supplements.

\section{Energy and Supplement Intake in SG Patients}

It seems that the most accessible and understandable form of nutritional recommendation for post bariatric surgery patients is the nutritional pyramid developed by Moizé et al. [21]. At the base of the pyramid is daily vitamin and mineral supplementation, because the result of a restrictive-type bariatric surgery is associated also with a deficiency in the intake of individual nutrients [22]. 
Table 3 Mean mineral dietary intake without or with supplements in patients tested at 3,6, and 9 months after bariatric surgery (SG)

\begin{tabular}{|c|c|c|c|c|c|c|c|}
\hline \multirow[t]{2}{*}{ Mineral intake } & \multicolumn{2}{|l|}{ Women $(n=24)$} & \multirow[t]{2}{*}{$p$ value } & \multicolumn{2}{|l|}{$\operatorname{Men}(n=6)$} & \multirow[t]{2}{*}{$p$ value } & \multirow{2}{*}{$\begin{array}{l}\text { OR } \\
(95 \% \mathrm{CI})^{* * *} \\
p \text { value } \\
n=30\end{array}$} \\
\hline & Without suppl & With suppl & & Without suppl & With suppl & & \\
\hline \multicolumn{8}{|l|}{$\mathrm{Na}$} \\
\hline Mean $\pm \operatorname{sd}(m g /$ day $)$ & $1263 \pm 361$ & $1263 \pm 361$ & $1.00 *$ & $1621 \pm 237$ & $1621 \pm 237$ & $1.00 *$ & - \\
\hline Intake from food $(\%)$ & & 100 & & & 100 & & \\
\hline Subject with intake < AI (\%) & 66.7 & 66.7 & $1.00 * *$ & 33.3 & 33.3 & $1.00 * *$ & \\
\hline \multicolumn{8}{|l|}{ K } \\
\hline Mean \pm sd (mg/day) & $2377 \pm 485$ & $2377 \pm 485$ & 1.00 & $2761 \pm 620$ & $2761 \pm 620$ & 1.00 & - \\
\hline Intake from food $(\%)$ & & 100 & & 100 & 100 & & \\
\hline Subject with intake $<$ AI $(\%)$ & 100.0 & 100.0 & 1.00 & 83.3 & 83.3 & 1.00 & \\
\hline \multicolumn{8}{|l|}{$\mathrm{Ca}$} \\
\hline Mean \pm sd (mg/day) & $510 \pm 142$ & $618 \pm 164$ & $<0.001$ & $576 \pm 175$ & $693 \pm 191$ & 0.038 & $5.80 * * *$ \\
\hline Intake from food $(\%)$ & & $72-100$ & & & $71-100$ & & $(0.63-53.01)$ \\
\hline Subject with intake $<$ EAR (\%) & 100.0 & 87.5 & 0.083 & 83.3 & 66.7 & 0.317 & 0.119 \\
\hline \multicolumn{8}{|l|}{$\mathrm{P}$} \\
\hline Mean \pm sd (mg/day) & $979 \pm 227$ & $1062 \pm 238$ & $<0.001$ & $1081 \pm 191$ & $1172 \pm 209$ & 0.038 & 1.00 \\
\hline Intake from food $(\%)$ & & $87-100$ & & & $88-100$ & & $(0.06-16.76)$ \\
\hline Subject with intake $<$ EAR (\%) & 4.2 & 4.2 & 1.00 & 0.0 & 0.0 & 1.00 & 1.00 \\
\hline \multicolumn{8}{|l|}{$\mathrm{Mg}$} \\
\hline Mean \pm sd (mg/day) & $220 \pm 46$ & $292 \pm 64$ & $<0.001$ & $247 \pm 40$ & $332 \pm 70$ & 0.039 & 15.17 \\
\hline Intake from food $(\%)$ & & $50-100$ & & & $66-100$ & & $(4.09-56.25)$ \\
\hline Subject with intake $<$ EAR $(\%)$ & 79.1 & 25.0 & $<0.001$ & 100.0 & 50.0 & 0.083 & $<0.001$ \\
\hline \multicolumn{8}{|l|}{$\mathrm{Fe}$} \\
\hline Mean \pm sd (mg/day) & $7.7 \pm 2.0$ & $12.1 \pm 3.6$ & $<0.001$ & $7.8 \pm 1.3$ & $12.2 \pm 3.5$ & 0.039 & 7.00 \\
\hline Intake from food $(\%)$ & & $35-100$ & & & $55-100$ & & $(1.38-35.48)$ \\
\hline Subject with intake $<$ EAR (\%) & 50.0 & 8.3 & 0.005 & 0.0 & 0.0 & 1.00 & 0.019 \\
\hline \multicolumn{8}{|l|}{$\mathrm{Zn}$} \\
\hline Mean \pm sd (mg/day) & $7.1 \pm 1.9$ & $11.5 \pm 3.8$ & $<0.001$ & $7.7 \pm 1.4$ & $11.9 \pm 3.3$ & 0.039 & 10.29 \\
\hline Intake from food $(\%)$ & & $29-100$ & & & $57-100$ & & $(2.56-41.37)$ \\
\hline Subject with intake $<$ EAR $(\%)$ & 45.8 & 8.3 & 0.003 & 83.3 & 16.7 & 0.046 & 0.001 \\
\hline \multicolumn{8}{|l|}{$\mathrm{Cu}$} \\
\hline Mean \pm sd (mg/day) & $0.8 \pm 0.2$ & $1.2 \pm 0.3$ & $<0.001$ & $1.0 \pm 0.2$ & $1.4 \pm 0.3$ & 0.039 & 8.83 \\
\hline Intake from food $(\%)$ & & $45-100$ & & & $59-100$ & & $(1.01-76.96)$ \\
\hline Subject with intake $<$ EAR (\%) & 29.2 & 4.2 & 0.014 & 0.0 & 0.0 & 1.00 & 0.049 \\
\hline \multicolumn{8}{|l|}{$\mathrm{Mn}$} \\
\hline Mean $\pm \mathrm{sd}(\mathrm{mg} /$ day $)$ & $3.4 \pm 1.1$ & $4.7 \pm 1.5$ & $<0.001$ & $4.4 \pm 1.0$ & $5.9 \pm 1.5$ & 0.034 & 1.00 \\
\hline Intake from food $(\%)$ & & $54-100$ & & & $63-100$ & & $(0.06-16.76)$ \\
\hline Subject with intake $<$ AI $(\%)$ & 4.2 & 4.2 & 1.00 & 0.0 & 0.0 & 1.00 & 1.00 \\
\hline
\end{tabular}

${ }^{*}$ Wilcoxon test; **McNemar test; ***odds ratio (95\% confidence interval) for subject intake > EAR/AI with vs. without supplementation; $p \leq 0.05$ statistically significant difference; $E A R / A I$ ref. value

Similar or even lower values of energy intake, than the values presented in our study, were also observed by Gjessing et al. [22], Moizé et al. [10], Verger et al. [11], Jastrzębska-Mierzyńska et al. [13], and Hosseini-Esfahani, et al. [14]. Soares et al. [23] documented that patients did not follow the recommendations laid out in the nutritional pyramid. The subjects were not systematically taking vitamin and mineral supplements and consumed too little fruits and vegetables. Schiavo et al. [24] showed that after 3, 6, 9, and 12 months after SG, the percentage of people who did not follow the recommended diet was $39 \%, 45 \%, 51 \%$, and $74 \%$, respectively, and those who did not follow the recommended supplementation was $43 \%, 51 \%, 59 \%$, and $67 \%$, respectively. Nonadherence to the recommendations regarding diet and vitamin-mineral supplementation after bariatric surgery has also been proven by other authors [3, 4, 25-31]. 
Fig. 2 Mean dietary and supplement micromineral intakes by women $(\mathbf{W})$ and men $(\mathbf{M})$ tested at 3,6 , and 9 months after bariatric surgery (SG) (all data expressed as $\mathrm{mg} /$ day)
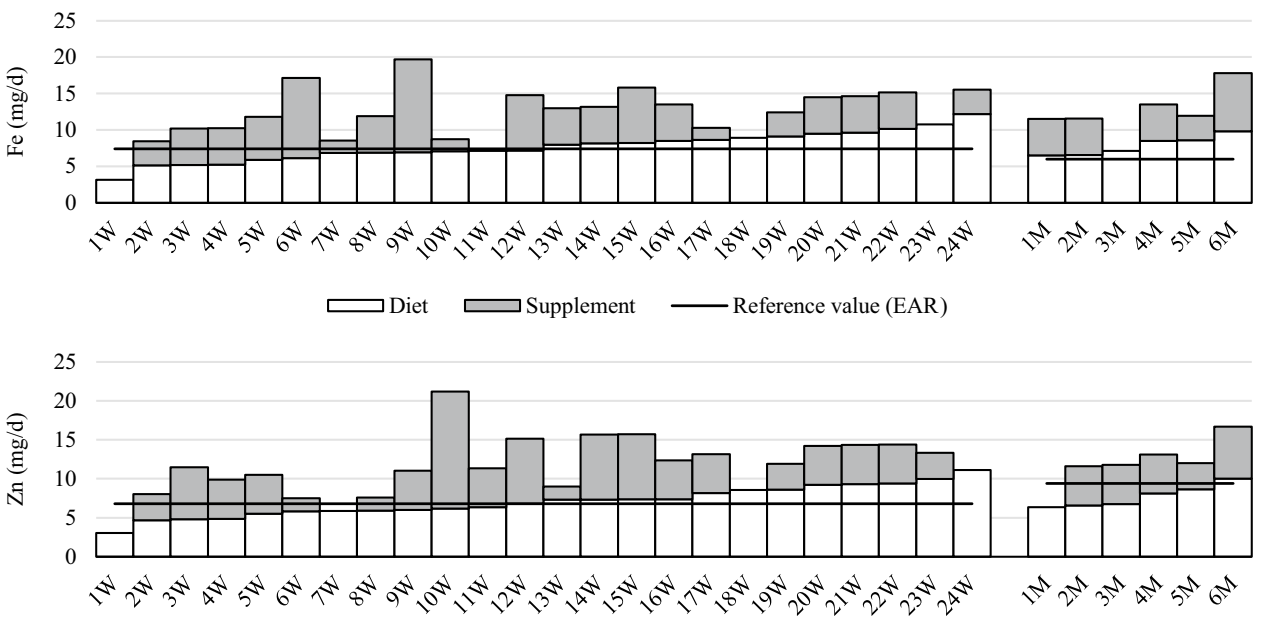

$\longleftarrow$ Diet $\square$ Supplement $\longrightarrow$ Reference value (EAR)
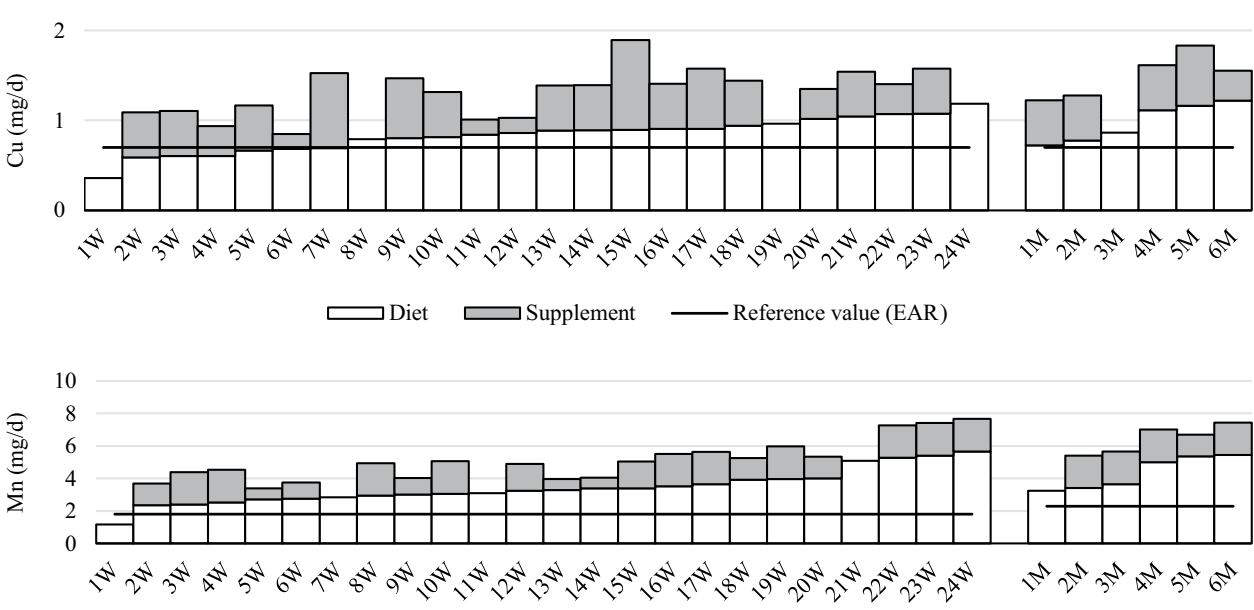

$\longleftarrow$ Diet $\longleftarrow$ Supplement $\longrightarrow$ Reference value (AI)

\section{Mineral Intake and the Need for Supplementation in SG Patients}

Patients' documented calcium intake before and/or after SG surgery was deficient [10, 12-14]. Moizé et al. [10] showed insufficient calcium intake through the diet, which concerned $75-90 \%$ of the subjects before and within 60 months post SG. Deficiencies in calcium intake have been documented in the studies of Hosseini-Esfahani et al. [14], a year after SG surgery (in $97.5 \%$ of patients), and Jastrzębska-Mierzyńska et al. [13], in all patients 3 and 6 months post SG. In the study of Chou et al. [12], patients did not take calcium at the recommended amounts 5 years after SG surgery. Calcium deficiency in the diet and an insufficient supply of vitamin D is unfavorable for a patient, because it is associated with the risk of osteoporosis and bone fractures [32, 33]. That is why the American Society for Metabolic \& Bariatric Surgery (ASMBS) recommends daily calcium supplementation for at least a year in the form of calcium citrate/carbonate in the amount of 1200-1500 mg post-surgery SG, RYGB (Roux en-Y gastric bypass), and AGB (adjustable gastric banding) [1, 34]; however, none of the patients implemented the supplementation at a level recommended by the ASMBS.

The incorrect intake of magnesium through diet, before and after surgery (after 6, 12, 24, 48, and 60 months), has been described in $87-100 \%$ of subjects in the Moizé et al. [10] study. Similarly, in the research of JastrzębskaMierzyńska et al. [13] and Hosseini-Esfahani et al. [14], deficiencies in magnesium intake were observed in $90 \%$ to $100 \%$ of respondents. Magnesium deficiencies may cause neuromuscular and cardiovascular disorders, insulin resistance, and impaired secretion of this hormone [19, 35]. In our own research, supplementation with this element also turned out to be insufficient, especially in women whose dietary magnesium intake was below $200 \mathrm{mg}$ /day and the magnesium supplement intake below $100 \mathrm{mg}$ in a daily dose. In men, a supplemental dose above $100 \mathrm{mg} /$ day enabled the effective reduction of nutritional deficiencies, due to their approximately $30 \%$ higher recommended intake value. 
Low sodium intake very rarely leads to its deficiency in the body [19]. After the SG surgery, the participants consumed smaller amounts of processed meat rich in sodium, and usually they did not salt their meals. They justified their behavior with the observation that a greater sodium intake would increase water retention in the body and as a consequence slow down weight loss. Sodium intake in our study was significantly lower than in the obese population qualified for bariatric surgery in the publication of JastrzębskaMierzyńska et al. [36], but similar to that reported by Chou et al. [12]. In the general population, salt intake greatly exceeds the recommended amounts, and therefore sodium is not intentionally incorporated into dietary supplements. The same applies to phosphorus, whose consumption with food usually exceeds recommendations, so there is no need for supplementation. Phosphorus in supplements occurs only as a salt component being the source of other elements. The supplements taken by the patients did not contain potassium. The study participants consumed insufficient quantities of vegetables, fresh and dried fruit, and cereals, products that are sources of potassium in the diet. Due to the fact that the kidneys have a large capacity to modify the supply of this element, the consequences of insufficient potassium intake are very rare [19]. Also Jastrzębska-Mierzyńska et al. [36] showed that before surgery the intake of potassium in $74 \%$ of women and $85 \%$ of men was too low.

Dietary iron deficiency post bariatric surgery has been documented by Moizé et al. [10]. Nonadherent dietary iron intake concerned 42 to $88 \%$ of the subjects at various time periods (before SG, $6,12,24,48$, and 60 months post-surgery). In the studies of Jastrzębska-Mierzyńska et al. [13], none of the women during the 3rd and 6th month post-surgery consumed iron according to the reference value, and none of the men in the study consumed iron 3 months post SG surgery. In the Hosseini-Esfahani et al. [14] study, only $30 \%$ of patients consumed adequate amounts of iron through diet. Dietary iron deficiency intake was also reported by Chou et al. [12]. Reduced daily intake and impaired iron absorption pose a threat of anemia. Symptoms of iron deficiency in patients include constant fatigue, impaired appetite, and pale skin. Limited consumption of iron-rich products (meat, whole grains, and selected vegetables) also promotes deficiencies. The use of a multicomponent supplement is often not effective and requires a one-component supplement. If oral supplementation is insufficient, iron can be taken intravenously or even a blood transfusion is necessary in critical cases [37, 38]. The iron supplemental dosage recommended by the American Association of Clinical Endocrinologists/Obesity Society/American Society for Metabolic \& Bariatric Surgery (AACE/TOS/ASMBS) to prevent iron deficiency after SG is at least $18 \mathrm{mg}$ and people at risk of anemia, a dosage of 45-60 mg [34, 39]. In our study, regardless of the supplemental dose taken (not less than $5 \mathrm{mg}$ ), all women (except for one woman who did not use supplements) achieved adequacy of iron intake. Dietary zinc intake lower than recommended by the AACE/ TOS/ASMBS [39] was demonstrated by Chou et al. [12], Hosseini-Esfahani, et al. [14] (in almost 90\% of respondents), and Jastrzębska-Mierzyńska et al. [13] (in all patients), because the consumption of zinc-rich products such as meat, liver, rennet cheese, whole-grain bread, buckwheat, and eggs decreases after bariatric surgery [25]. Zinc deficiencies in the diet are a risk factor for decreased immunity and hypothyroidism [19]. In our study, insufficient zinc intake was observed only in patients who did not implement supplementation of at least $5 \mathrm{mg} /$ day.

All researchers agree that supplementation post SG is necessary because the diet does not meet the recommended intake of some minerals, most often calcium, magnesium, and iron $[10,34,40]$. Most researchers propose systematic daily supplementation according to ASMBS guidelines for 1 year after surgery; however, some nutritional deficiencies in the body occur even a few years later [39].

A strength of this study is that the analysis took into account the need for supplementation. Existing studies do not assess to what extent supplementation practice corrects insufficient dietary intake. None of the studies covered such a broad range of minerals and long time period (3-9 months) after the procedure, as in our study. Moreover, other studies did not assess whether supplementation practice led to exceeding safe levels. Our study is subject to a number of limitations. The study was conducted on a small group of men, which is related to the fact that the majority of patients undergoing surgical treatment for obesity are women. The second important limitation is that the study considered mineral intake only and did not apply nutritional status parameters of the patients (blood levels were not measured). Another limitation was finishing the study 9 months after surgery, due to the fact that fewer women and no men had nutrition follow-up after 9 months. However, the results of this study confirm that supplementation with selected minerals post SG surgery is necessary and safe and also indicates that bariatric patients need individually tailored dietary consultations to prevent nutritional deficiencies.

\section{Conclusions}

To improve the implementation of dietary recommendations in women, special attention should be paid to correct calcium intake with dietary supplements and in men to correct calcium and magnesium intake. In all of our patients, zinc supplementation as well as the supplementation of iron and copper in women properly adjusted deficient intake from food products. Both men and women should be encouraged to modify their diet to improve potassium and sodium intake 
as both minerals are not usually recommended in the form of supplements. Phosphorus and manganese supplementation proved to be unjustified in all subjects, as well as iron and copper in men.

Acknowledgements The authors wanted to thank Professor Wiesław Tarnowski the Head of the Department of General, Oncological and Digestive Tract Surgery, Medical Center of Postgraduate Education, Orlowski Hospital, Warsaw, Poland, for enabling the study and for his assistance and great support.

Author Contribution AW and MK conceptualization, methodology, project administration, writing - review and editing. MK investigation, data curation. AW statistical analysis, funding acquisition, supervision, writing - original draft preparation, corresponding author.

Funding This research received no external funding and this study was performed under the project of the Institute of Human Nutrition Sciences, Warsaw University of Life Sciences (SGGW-WULS), Poland (No. 505-50-780200-FN0000-99).

\section{Declarations}

Ethics Approval and Consent to Participate The study was conducted according to the guidelines of the Declaration of Helsinki and approved by the Bioethical Commission of the Centre of Post-graduate Education on April 12, 2017 (KB-W-382/2017). Informed consent was obtained from all subjects involved in the study.

Conflict of Interest The authors declare no competing interests.

Open Access This article is licensed under a Creative Commons Attribution 4.0 International License, which permits use, sharing, adaptation, distribution and reproduction in any medium or format, as long as you give appropriate credit to the original author(s) and the source, provide a link to the Creative Commons licence, and indicate if changes were made. The images or other third party material in this article are included in the article's Creative Commons licence, unless indicated otherwise in a credit line to the material. If material is not included in the article's Creative Commons licence and your intended use is not permitted by statutory regulation or exceeds the permitted use, you will need to obtain permission directly from the copyright holder. To view a copy of this licence, visit http://creativecommons.org/licenses/by/4.0/.

\section{References}

1. Gletsu-Miller N, Wright BN. Mineral malnutrition following bariatric surgery. Adv Nutr. 2013;4:506-17.

2. Welbourn R, Hollyman M, Kinsman R, et al. Bariatric surgery worldwide: baseline demographic description and One-year outcomes from the fourth IFSO Global Registry Report 2018. Obes Surg. 2019;29:782-95.

3. Gillon S, Jeanes YM, Andersen JR, et al. Micronutrient status in morbidly obese patients prior to laparoscopic sleeve gastrectomy and micronutrient changes 5 years post-surgery. Obes Surg. 2017;27:606-12.

4. Busetto L, Dicker D, Azran C, et al. Practical recommendations of the obesity management task force of the European Association for the Study of Obesity for the Post-Bariatric Surgery Medical Management. Obes Facts. 2017;10:597-632.

5. Walędziak M, Różańska-Walędziak A, Kowalewski PK, et al. Present trends in bariatric surgery in Poland. Wideochir Inne Tech Maloinwazyjne. 2019;14:86-9.

6. Fried M, Hainer V, Basdevant A, et al. Interdisciplinary European guidelines on surgery of severe obesity. Int $\mathrm{J}$ Obes. 2007;31:569-77.

7. Rawlins L, Rawlins MP, Brown CC, et al. Sleeve gastrectomy: 5-year outcomes of a single institution. Surg Obes Relat Dis. 2013;9:21-5.

8. Lupoli R, Lembo E, Saldalamacchia G, et al. Bariatric surgery and long-term nutritional issues. World J Diabetes. 2017;8:464-74.

9. Palermo M, Serra E. Laparoscopic sleeve gastrectomy: how do I do it. J Laparoendosc Adv Surg Tech A. 2020;30:2-5.

10. Moizé V, Andreu A, Flores L, et al. Long-term dietary intake and nutritional deficiencies following sleeve gastrectomy or Roux-En-Y gastric bypass in a Mediterranean population. J Acad Nutr Diet. 2013;113:400-10.

11. Verger EO, Aron-Wisnewsky J, Dao MC, et al. Micronutrient and protein deficiencies after gastric bypass and sleeve gastrectomy: a 1-year follow-up. Obes Surg. 2016;26:785-96.

12. Chou JJ, Lee WJ, Almalki O, et al. Dietary intake and weight changes 5 years after laparoscopic sleeve gastrectomy. Obes Surg. 2017;27:3240-6.

13. Jastrzebska-Mierzynska M, Ostrowska L, Duchnowska E, et al. Assessment of energy intake and selected nutrients within 6 months after laparoscopic sleeve gastrectomy. Post N Med. 2018;31:144-9.

14. Hosseini-Esfahani F, Khalaj A, Valizadeh M, et al. Nutrient intake and deficiency of patients 1 year after bariatric surgery: Tehran Obesity Treatment Study (TOTS). J Gastrointest Surg. 2020. https://doi.org/10.1007/s11605-020-04530-9.

15. Kulick D, Hark L, Deen D. The bariatric surgery patient: a growing role for registered dietitians. J Am Diet Assoc. 2010;110:593-9.

16. Kichler K, Rosenthal RJ, DeMaria E, et al. Reoperative surgery for nonresponders and complicated sleeve gastrectomy operations in patients with severe obesity an international expert panel consensus statement to define best practice guidelines. Surg Obes Relat Dis. 2019;15:173-86.

17. Szponar L, Wolnicka K, Rychlik E. Album fotografii produktów i potraw (eng Photo album of products and dishes). Warsaw: Institute of Food and Nutrition; 2000.

18. Kunachowicz H, Przygoda B, Nadolna I, et al. Tabele składu i wartości odżywczej żywności (eng Tables of nutritional value of food). Warsaw: PZWL; 2017.

19. Jarosz M. Normy żywienia dla populacji Polski (eng Dietary for the Polish population). Warsaw: Institute of Food and Nutrition; 2017.

20. EFSA. Summary of tolerable upper intake levels, version 4, September 2018. https://www.efsa.europa.eu/sites/default/files/ assets/UL_Summary_tables.pdf.

21. Moizé VL, Pi-Sunyer X, Mochari H, et al. Nutritional pyramid for post-gastric bypass patients. Obes Surg. 2010;20:1133-41.

22. Gjessing HR, Nielsen HJ, Mellgren G, et al. Energy intake nutritional status and weight reduction in patients one year after laparoscopic sleeve gastrectomy. Springerplus. 2013;2:352.

23. Soares FL, Bissoni de Sousa L, Corradi-Perini C, et al. Food quality in the late postoperative period of bariatric surgery: an evaluation using the bariatric food pyramid. Obes Surg. 2014;24:1481-6.

24. Schiavo L, Scalera G, Pilone V, et al. Patient adherence in following a prescribed diet and micronutrient supplements after laparoscopic sleeve gastrectomy: our experience during 1 year of follow-up. J Hum Nutr Diet. 2017;30:98-104. 
25. Freeman RA, Overs SE, Zarshenas N, et al. Food tolerance and diet quality following adjustable gastric banding sleeve gastrectomy and Roux-en-Y gastric bypass. Obes Res Clin Pract. 2014;8:e115-200.

26. Dunstan MJ, Molena EJ, Ratnasingham K, et al. Variations in oral vitamin and mineral supplementation following bariatric gastric bypass surgery: a national survey. Obes Surg. 2015;25:648-55.

27 Hood MM, Corsica J, Bradley L, Vivo A, et al. Managing severe obesity: understanding and improving treatment adherence in bariatric surgery. J Behav Med. 2016;39:1092-103.

28. James H, Lorentz P, Collazo-Clavell ML. Patient-reported adherence to empiric vitamin/mineral supplementation and related nutrient deficiencies after Roux-en-Y gastric bypass. Obes Surg. 2016;26:2661-6.

29. Zarshenas N, Nacher M, Loi KW, et al. Investigating nutritional deficiencies in a group of patients 3 years post laparoscopic sleeve gastrectomy. Obes Surg. 2016;26:2936-43.

30. Ben-Porat T, Elazary R, Goldenshluger A, et al. Nutritional deficiencies four years after laparoscopic sleeve gastrectomyare supplements required for a lifetime? Surg Obes Relat Dis. 2017;13:1138-44.

31. Pellitero S, Martínez E, Puig R, Leis A, et al. Evaluation of vitamin and trace element requirements after sleeve gastrectomy at long term. Obes Surg. 2017;27:1674-82.

32. Dagan SS, Goldenshluger A, Globus I, et al. Nutritional recommendations for adult bariatric surgery patients: Clinical Practice. Adv Nutr. 2017;8:382-94.

33. Ben-Porat T, Elazary R, Sherf-Dagan S, et al. Bone health following bariatric surgery: implications for management strategies to attenuate bone loss. Adv Nutr. 2018;9:114-27.

34. Parrott J, Frank L, Rabena R, et al. American Society for Metabolic and Bariatric Surgery Integrated Health Nutritional
Guidelines for the Surgical Weight Loss Patient 2016 Update: Micronutrients. Surg Obes Relat Dis. 2017;13:727-41.

35. Morais JBS, Severo JS, de Alencar GRR, et al. Effect of magnesium supplementation on insulin resistance in humans: a systematic review. Nutrition. 2017;38:54-60.

36. Jastrzębska-Mierzyńska M, Ostrowska L, Razak H, et al. Assessment of dietary habits nutritional status and blood biochemical parameters in patients prepared for bariatric surgery: a preliminary study. Wideochir Inne Tech Maloinwazyjne. 2012;7:156-65.

37. Gehrer S, Kern B, Peters T, et al. Fewer nutrient deficiencies after laparoscopic sleeve gastrectomy (SG) than after laparoscopic Roux-Y-gastric bypass (LRYGB) - a prospective study. Obes Surg. 2010;20:447-53.

38. Stein J, Stier C, Raab H, et al. The nutritional and pharmacological consequences of obesity surgery. Aliment Pharmacol Ther. 2014;40:582-609.

39. Mechanick JI, Apovian C, Brethauer S, et al. Clinical practice guidelines for the perioperative nutrition metabolic and nonsurgical support of patients undergoing bariatric procedures - 2019 update: cosponsored by American Association of Clinical Endocrinologists/American College of Endocrinology, the Obesity Society, American Society for Metabolic \& Bariatric Surgery, Obesity Medicine Association and American Society of Anesthesiologists. Surg Obes Relat Dis. 2020;16:175-247.

40. Thibault R, Huber O, Azagury DE, et al. Twelve key nutritional issues in bariatric surgery. Clin Nutr. 2016;35:12-7.

Publisher's Note Springer Nature remains neutral with regard to jurisdictional claims in published maps and institutional affiliations. 